\title{
'Miss mum': Mind and affective experience of Korean learners identified with Autism Spectrum and cognitive difficulties
}

\begin{abstract}
Responding to the call for culturally informed research on Autism Spectrum (AS) to allow for the provision of appropriate services, this paper qualitatively explores the affective experience of five Korean learners identified with AS and cognitive difficulties by listening to their voices. The learners, supported by the use of visual aids and a choice of their preferred mode of communication, expressed the complexity of their inner experience that encompassed abilities as well as difficulties. The findings highlight the commonalities of experience between Korean and non-Korean individuals with AS, along with some aspects specific to the Korean cultural context.
\end{abstract}

Keywords: autism; cognitive difficulties; affective experience; qualitative inquiry; Korean culture; mind

'If my return to who I am was guaranteed, I would like to become autistic for a day.' As pre-service special education teachers in Republic of Korea encountering students with Autism Spectrum (AS), we spoke of our desire to know what it is like to be autistic. Later I became responsible for 26 students with a wide range and severity of disabilities, including AS, at a mainstream primary school catering for over 3000 students. Each day was a struggle.

This paper qualitatively explores the affective experience of Korean students identified with AS and intellectual difficulties by facilitating their communication. As my approach to investigating the experience of individuals with AS has been influenced by my background as a teacher, I will refer to my teaching experience in contexts where it seems appropriate.

\section{Viewing Autism Spectrum}

AS has been viewed from a number of different perspectives. For cognitive theorists such as Frith and Happé (1999), its core symptoms are due to difficulty in 
the capacity to attribute mental states and predict behaviour. Called Theory-of-Mind (ToM), the presence or absence of this capacity is established through psychological testing. Failure in false belief tests evidence a 'deficit' in ToM and the presence of what Baron-Cohen calls 'mindblindness' $(1995,5)$. As for how this would be subjectively experienced, Frith and Happé $(1999,7)$ speculated that 'individuals with AS may know as little about their own mind as about the minds of other people'.

I remember an encounter with Yongjun, a student with AS, during a school camping trip. On the second night we were standing near the fire when he said, in a trembling, high mono-toned voice, ‘(I) miss my mum!’ His mother had separated from her husband and two children, both of whom had AS, because of on-going family problems. The silhouettes of the flames played around his face. He was weeping, as was I. I pulled out my mobile phone. We looked at it and then at each other. I rang his mother and handed the phone to him. I listened to the ring tones and his cry of 'Mum!' After the call, we walked together to where his classmates were waiting for him.

I find that my memories of my students on the spectrum do not necessarily comply with the analysis provided by ToM researchers. I do not know whether Yongjun attributed sadness to himself when he said he missed his mother. However, I wonder how he could have said this without feeling, and knowing what he felt. I do not know if he attributed sadness to me when I wept at his confession, or if he predicted my behaviour of phoning his mother and the doubt, fear and desire I felt. However, I do know we trusted each other and were willing to express our feelings and thoughts to each other.

McGeer (2004, 236) criticises attempts to explain a wide range of autistic symptoms by one core cognitive marker (i.e. ToM), because this 'underestimates the 
importance of other noncognitive features'. She focuses on the role of sensory sensitivity and suggests that sensory abnormalities could lead to higher-order socialcognitive problems, rather than the other way around. Commenting on autistic selfreports, McGeer (2004) also points out that the very desire to be understood by others, and the pain expressed at not being understood, indicate a degree of empathy that, in cognitive theory, should not exist.

This concern was echoed by Gipps (2004), who stressed how difficulties in mental state ascription and behaviour prediction may arise from disturbances in interpersonal relatedness. Hobson (2008) explained AS through difficulties in how we enter shared forms of life, arguing that individuals with AS are compromised in their social-affective relatedness. He also stressed that these limitations are partial rather than absolute, that individuals with AS do share a form of life with others, although to a limited degree. In other words, an either-or approach is too crude to cover the complexity of the range of autistic experience.

\section{Attending to autistic voices}

Further concerns about ToM studies come from people with AS themselves (e.g. Bovee 2000; Grandin 2006), who view the absence of their own voices in them as problematic given they are about their own inner worlds. I share these concerns, and regret not realising the importance of asking my students with disabilities about their feelings and thoughts when I was a teacher.

I re-united with Yongjun and his mother after seven years. He had turned into a self-disciplined and filial son who exercised regularly and cleaned the house to help his mother. This behaviour began when his mother, worried about Yongjun’s social difficulties, returned to her children and husband. The changes that Yongjun and his mother went through illustrate how a simple deficit approach to AS fails to reflect the 
complexities of real life. This complexity can be accommodated by qualitative studies that include the voices of people with AS (Anzul et al. 2001).

People with AS, however, rarely participate in qualitative studies (Chamak et al. 2008), in particular those who also have cognitive difficulties. In fact, existing qualitative studies (e.g. Chamak et al. 2008; Carrington, Papinczak, and Templeton 2003) and autobiographies (e.g. Tammet 2006) have been concerned exclusively with individuals with high functioning autism (HFA) without cognitive difficulties. All this shows the need for the development of research methods that allow the voices of people with AS and cognitive difficulties to be heard (O'Neil 2008). Image-based research can contribute, since it helps individuals articulate ideas and understandings in ways written or spoken language may not (Hopperstad 2010).

Images are often used as icebreakers to elicit responses from interviewees, including disadvantaged children (Prosser and Burke 2008). Indeed, image-based research has been conducted to explore the concepts of self and identity in young children (e.g. Shanban and Al-Awidi 2013) and the views and experience of children and young people with AS (e.g. Humphrey and Lewis 2008).

\section{Autism Spectrum Disorders within the Korean cultural context}

Daley (2002) views AS as culturally shaped, and stresses the importance of studying it within its particular cultural context, which can help in the development of culturally relevant educational services (Kang-Yi, Grinker, and Mandell 2013). Looking at the Korean context, Korea has a very high AS prevalence rate of 2.46\% among school-aged children (Kim et al. 2011) as well as negative cultural connotations associated with the condition, such as familial dishonour and shame. Mothers are reluctant to accept an AS diagnosis because of their fear that it might threaten the marriage prospects of members of the autistic person's extended family 
(Grinker and Cho 2013). As main care providers mothers frequently experience signs of public displeasure, and they struggle with a lack of informal support from family members and formal support from paid professionals (Cho, Singer, and Brenner 2000). In a society where Confucian values are still strong, some Korean siblings feel that they are expected to make life-time sacrifices for the sake of family harmony and the well-being of their autistic siblings (Hwang and Helen 2010). This paper explores the affective experience of learners identified with AS and intellectual difficulties within this particular social and cultural context.

\section{Methods}

\section{Learners}

This study was conducted in three special schools in Seoul, Republic of Korea, that cater for students with AS and emotional disorders. It is part of a larger study using mixed research methods to explore the inner experience of 20 students with AS and cognitive difficulties, where the results highlighted the complexity of the minds of students with AS along with the difficulties their teachers have in attributing mental states to them (Hwang 2009). This paper focuses on the affective experience of five male students chosen for their relatively rich expressive communication. Their interview data were re-analysed to maximise opportunities for their individual voices to be heard.

Table 1 presents the participants, including their social age (range 5:9 - 8:83) as evaluated by their teacher or mother using the Social Maturity Scale (Kim and Kim 1985). The Social Maturity Scale (SMS) is the Korean version of the Vineland Social Maturity Scale standardised for Koreans with and without disabilities. In the communication domain of the SMS, all participants could read simple reading 
materials and legibly write more than 12 words. In addition, Dongmin, Jaeyong and Woohyung could make a phone call, and Dongmin and Jaeyong enjoyed reading a variety of media such as books, newspapers or magazines.

The school assessment teams recognised them as having AS and limitations in intellectual abilities, yet they were officially diagnosed only with intellectual disabilities. This is because until 1999, when the Welfare of Disabled Persons Act extended legal entitlement for social work services to people with AS, most individuals with AS in Republic of Korea were diagnosed as having an intellectual disability (Huh 2009). Therefore the term AS in this paper is used in a general sense without reference to medical diagnosis.

\section{[Insert Table 1]}

\section{Assisting communication difficulties}

The affective experience of learners was studied through individual semistructured interviews. Although the participants could read and write, they still had communication difficulties. Visual aids were used to contextualise and concretise interview questions, and included (a) facial drawings depicting the emotions of happiness, sorrow, anger and fear, (b) drawings of scenarios calling for a response appropriate to these four emotions, and (c) two drawings created by the learners themselves, a self-portrait and a portrait of a friend.

Facial drawings were used to establish agreement on the meaning of each emotion. The four scenarios deepened conversation with participants regarding their emotions. The scenarios represented (a) happiness (being given a cupcake); (b) fear (coming back home to a dark and empty house); (c) sadness (being unable to go shopping with mother because of sickness); and (d) anger (having a pen taken away while drawing). These scenarios were selected by five Korean special education 
teachers from the intervention workbook, Teaching children with autism to mindread: A practical guide for teachers and parents (Howlin, Baron-Cohen, and Hadwin 1999), to ensure the cultural relevance and age appropriateness of research materials. Interviews progressed into open conversations, unsupported by pre-selected drawings and scenarios, about the inner experience of the learners. Self-determination was practised by allowing learners their choice of communication mode, between speaking and writing. Learners who preferred spoken communication used word cards with interview questions. An interview booklet created from the questions facilitated written communication. For example, the question, 'When do you feel sad?' was written as the self-completion statement, 'I feel sad when ( ).' Drawing activities further assisted conversation, as they spoke about themselves while producing a selfportrait and a portrait of their friend.

As with Carrington, Papinczak and Templeton (2003), who interviewed five Australian secondary students with Asperger Syndrome, the five Korean learners required a great deal of prompting and rewording of the questions. While there was always the possibility that the learners felt pressured to answer my questions, I was alert to this and monitored my conversational style to prevent it. To minimise disruptions of their routines, the learners were informed and reminded of their interview times and venues. The Human Research Ethics Committee (HREC) of the University of Sydney approved this study. All names are pseudonyms.

\section{Making sense of the data}

Overall, responses from the participants were brief, composed mainly of one or two words or phrases (e.g. happy, like it, bad, love mum). Interview data were analysed through thematic analysis following a step-by-step guide provided by Braun and Clarke (2006). Analysis involved a naming process that highlighted the unique 
nature of the basic segments of the data, generating 353 initial codes with 558 interview extracts. One phrase or sentence could be coded in multiple ways and when a new code was generated, previously coded interview transcriptions were revisited to find and extract any relevant data segments.

Codes concerning affective experience were collated according to experiencing subject (e.g. feeling good-I and feeling good-others) and any intriguing aspect that appeared frequently. These gave rise to themes. Frequently appearing key words (e.g. mother, being alone, being with friends) and memos written during the initial coding stage played a crucial role in finding themes. I looked for any qualities in the codes that could bring them into relationship. For example, ambivalence, a quality hidden in the initial data, emerged as a main theme that overarched a number of conflicting experiences. Four main themes emerged (Figure 1). They are discussed in the following sections.

\section{[Insert Figure 1]}

\section{Results and discussion}

\section{Affection expressed for ...}

Learners expressed affection towards a variety of people and things. In response to the questions, 'Who do you like?' and 'Who do you love?', all mentioned their parents and siblings. Among family members their affective bond with 'mum' ('umma,' an informal word for mother that indicates intimacy) was strongest. She was the person most frequently associated with love and liking. All learners expressed affection for their 'dad' ('appa,' informal for father) and siblings, but with one exception they were mentioned only after mum. 
Mothers and fathers were perceived differently. Mum was associated with 'home' and 'being' while dad was associated with ‘outside' and 'doing'. This seems to reflect the clear distinction between male and female family roles in Korea where Confucian values are still strong (Kim and Faerman 2013). For example, Dongmin enjoyed being at home with his mum, who loved him, and going out to soccer games with his dad, who did 'good things' for him by going to work. Doori put forward his mother as a person he likes before his father and younger brother. Sunghoon identified his mother as someone he wanted to assist, and his father and sister as people he wanted to be assisted by.

Cho, Singer and Brenner (2000) have described the Korean family structure as mother undertaking the primary care provider's role, with little domestic and social support, and father largely absent, even after working hours. This structure appears to provide a background to the strong bond between the learners and their mothers, and the different perceptions noticed for mum (home and being) and dad (outside and doing).

Dongmin, Doori, Jaeyong and Sunghoon also identified themselves as someone they loved. They confined 'love' to family members and themselves, except Dongmin who also mentioned his schoolmates. 'Liking' extended to people beyond the family such as classmates, teachers and the researcher. The range of people these learners loved and/or liked is limited for boys in their late teens, corresponding with the findings of studies in other cultural contexts (e.g. Carrington, Papinczak, and Templeton 2003) that reported a restricted range of interests shown by people with AS. Affection for family seems universal, regardless of culture, although the degree of immersion within the family may be stronger among these learners. 


\section{Ways of expressing affection}

All learners expressed their affection, either by speaking (e.g. 'Love mum’) or writing (e.g. 'Love Jaeyong'), sometimes accompanied by non-verbal expressions. Talking about family members, Dongmin raised his voice tone and made a hugging gesture, and Sunghoon made a heart symbol with his arms and a hugging gesture. Woohyung expressed his affection for his teacher verbally and by raising his arms in a big circle. Dongmin, Doori, Woohyung and Sunghoon expressed affection for the researcher during the interviews by making frequent high-fives and smiling.

\section{Feelings expressed clearly}

All learners used a variety of words to describe feelings they have experienced for themselves (e.g. angry, bad, distressed, glad, good, hurt, sad, scared, sulky) and found in others (e.g. angry, bad, glad, good, sad, struggling, sulky, surprised, worried), including those induced by the scenarios (e.g. angry, bad, glad, good, sad, sulky, scared). While all learners expressed pleasant feelings more frequently (e.g. glad, good), they used a wider variety of words to convey unpleasant feelings (e.g. angry, bad, distressed, hurt, sad, scared, sulky). In addition, while all identified themselves with good and sad feelings, only some did so with scared, angry and distressed feelings.

Dongmin felt good, particularly at home with his mum, at school and going to the football with his dad when Seoul FC, their team, wins. For Sunghoon being alone, eating instant noodles, and watching TV make him feel good. Singing and feeling good appear to be closely associated. Sunghoon, asked about his feeling during the interviews, started singing and said 'Good'. Dongmin also sang during an interview break and Jaeyong associated singing with good feelings, especially at school karaoke. 
Sadness and sickness were closely linked. All learners reported that they felt sad or bad in response to a question or self-completion statement concerning their mother getting sick. These responses indicate empathy, even if the expressions were brief. Doori wrote '(I) feel sad when mum is sick' and made weeping sounds. Woohyung wanted to comfort and Doori felt like crying when their brother was sad. If empathy is an affective response towards another's feelings or situation rather than one’s own (Hoffman 2000), then these responses appear to indicate empathy.

In the provided situations learners also recognised the empathy of their family members when they themselves were sick or happy. They all responded that their mother experienced unpleasant feelings (e.g. scared, sad, bad, dislike) when they were sick and pleasant feelings (e.g. good, glad) when they were happy. These examples suggest that an apparent lack of empathy may indicate weak communication skills rather than the absence of empathy (Gesaroni and Garber 1991), and they support, along with autistic narratives concerning empathy (e.g. McMullen 2000), recent studies reporting relatively intact affective empathy in people with AS (e.g. Rogers et al. 2007). All this casts doubt on the view that sees impairments in empathy as central to AS (e.g. Gillberg 1992).

Jaeyong felt distressed when angry and sad when sick. Sad and mum were also related. Mum leaving him behind made Woohyung sad, while being with mum at home made Sunghoon sad. Sunghoon also sometimes associated sad with angry.

Researcher: What do you do when you are angry?

Sunghoon: Because sad.

Researcher: Uh (agreeing sound).

Sunghoon: Ask for a tissue.

Researcher: Ask for a tissue when angry? 
Sunghoon: Ask for (meaning agreement).

Researcher: I see. Is there anything else? When angry?

Sunghoon: Wipe tears with a tissue.

Researcher: Wipe tears with a tissue?

Sunghoon: Yes, cry at a tissue.

Researcher: Cry at a tissue.

Some studies have discussed autistic sensitivity to one’s own unpleasant feelings (Boucher 1996), indicated in this study by learners’ wider range of expressions used to depict their unpleasant feelings compared to their pleasant ones. The same is true in regard to the feelings of others. The unpleasant feelings of others were expressed by angry, bad, dislike, sad, struggling, sulky, and worried, as opposed to just glad and good for their pleasant feelings.

Dongmin recognised his dad's good and sad feelings depending on whether their soccer team won or lost. Jaeyong identified a bad feeling in his classroom teacher when he swore, as she did not like him doing so. Sunghoon said his classmate would feel good if his mum bought a cake for him, and his own mother would feel dislike in response to his angry behaviour. Woohyung recognised that others feel good and bad depending on whether or not they see people they like.

\section{Feelings expressed with difficulty}

These learners also demonstrated difficulties in identifying and expressing feelings, as revealed by their focus on the physical features of faces when asked to identify feelings. Regarding the facial drawings depicting four basic emotions, Woohyung and Jaeyong described the weeping image as crying rather than sadness. Dongmin said smile when asked to identify a feeling from a drawing depicting happiness. Hobson (2008) discussed how weaknesses in intersubjective understanding 
directly affect the interpersonal relationships of people with AS. Dongmin's understanding of his teacher's response to his misbehaviour in classroom provides an example.

Researcher: When you scream during study time, how does teacher Choi feel about this?

Dongmin: Say, leave the room.

Researcher: Yes, she said leave the room. Then what is her feeling when it happens?

Dongmin: Get out of the way.

Researcher: Yes, get out of the way. Then, what is your teacher's feeling? Dongmin: Running.

Researcher: Running. Yes. Then how does your teacher feel?

Dongmin: Be punished.

Doori would feel sad if he cannot go to Lotte world, his favourite place, but the researcher who also would like to go there would feel good if she cannot make it. Doori also said his friend would feel good if he hit him, but he would feel hurt if he was hit.

Hobson (2008) rejects an either-or approach to autistic experience and stresses the importance of acknowledging the partial capacity of individuals with AS to engage in interpersonal relationships. The five learners in this study demonstrated individual differences in their interpersonal relationships, where some had more difficulties than others, and even within an individual learner, where at times a learner would or would not demonstrate difficulties. There was, however, no learner who demonstrated a total absence of interpersonal relatedness. 


\section{Perceptions of self and friends}

During interviews each learner produced a self-portrait and a portrait of their friend (Figure 2-11). Subject-produced drawings of the human figure (e.g. selfportraits) have been analysed against developmentally sequenced cognitive abilities (Ganesh 2011), while another approach acknowledges children's drawings as expressions conveying meanings embedded within their social and cultural context (Shanban and Al-Awidi 2013). In line with the latter approach, the learner-produced drawings were analysed according to their ideal meaning as described by the drawers (i.e. what an image represents) and their interpersonal meaning (i.e. the way they addresses their potential viewers, through either a direct or indirect gaze) (Hopperstad 2010).

The learners identified the subjects of their drawings, indicating they remembered their intention to represent themselves and their friend. They generally demonstrated a positive self-image, as the majority identified a good feeling in their self-portrait and named themselves as someone they liked or loved. Most referred to themselves with their own name instead of using the personal pronoun. They perceived many people as their friends and expressed mixed feelings, both good and bad, about being in their company. Classmates and family members were named as friends, along with God and an apartment company name. Their perceptions of self and friends appeared fluid, however, as three of the five learners saw themselves as their own friend. All portraits, of self and friend, looked directly at their potential viewers.

Dongmin drew a head only for himself and described it as a person who felt good and preferred to be alone. Asked to draw his friend, he again drew himself. 
Asked to provide another friend, he eventually drew a classmate with whom he enjoyed playing computer games and surfing the internet.

\section{[Insert Figure 2]}

\section{[Insert Figure 3]}

Doori was often slow to respond to questions and required prompting. When asked whom he loved, he wrote, 'Love Mum, Dad, Woori (his brother), Doori’. He named himself as his friend, along with his family members. Asked to draw a portrait of a friend, he drew Woori, his younger brother. He also saw God as his friend and said 'praising' was what God and Doori did to each other. Asked to demonstrate what this meant, he was silent. Doori also produced more conventional figures, containing a complete vertical segmentation of head, chest, legs, feet and arms (Cox 1993).

\section{[Insert Figure 4]}

\section{[Insert Figure 5]}

Looking at his drawing of himself, Jaeyong recognised a good feeling in it but remained silent when he was asked why he felt good. He also referred to himself with his own name, and named himself as someone he loved and liked before anyone else. Jaeyong was very clear about seeing himself as his own friend, since he repeatedly wrote and spoke about this. He said he and a classmate he drew as his friend liked each other, but he also expressed fear in being with him. In Jaeyong's drawings the torso is attached to the head.

\section{[Insert Figure 6]}

\section{[Insert Figure 7]}

Sunghoon, a 16 year-old boy, drew himself as a 12 year-old girl and identified himself as feeling good and pretty. Sunghoon mentioned his own name as someone he loved and frequently referred to himself by name. For example, he said his younger 
sister was angry with 'Sunghoon' rather than with 'me'. Although he provided a long list of classmates as friends, when asked to draw a friend he drew her. For both portraits Sunghoon drew a head only, and he added scribbles to his self-portrait.

\section{[Insert Figure 8]}

\section{[Insert Figure 9]}

When Woohyung drew himself and wrote down his name, the researcher realised she was calling him by the wrong name. She apologised and Woohyung smiled and said 'Yes' (indicating acceptance). With a beaming smile he then said he felt good. Woohyung was the only one who did not refer to himself by his name. He expressed himself briefly without using subjects, yet his expressions were precise and he consistently used honorifics, a feature of polite Korean. He often responded with 'Don't know' or kept silent, especially when asked about friends. Later he said he did not have a friend but identified a classmate as someone he would like to sit next to, and drew him when portraying his friend. Both of his portraits contained vertical segmentations of the body.

\section{[Insert Figure 10]}

\section{[Insert Figure 11]}

When learners explained what they did together with their friend, their responses were brief but expressive. Dongmin said Jaeyong did 'precious part' to him and Dongmin did 'keeping part' to Jaeyong. Jaeyong wrote that his friend, Minyoung, 'brings a milk carton' to him (as part of the meal provided by the school) and he does 'Cheon, Moo-Song' to his friend. Although he explained that Cheon, Moo-Song is an actor, he did not elaborate on what doing Cheon, Moo-Song entails.

Responding to what they would like to do for a sick friend the learners were brief but compassionate, which again challenges the view that lack of empathy is a 
core AS character. Dongmin said and wrote that he would like to 'contact' a sick friend. Doori said he 'would like to be a friend' and Jaeyong wrote, 'Heal'. Woohyung said he would like to 'console' his elder brother when he is sick and crying.

The learners' focus on a restricted range of activities and interests and their desire for friendship are also found by Carrington, Papinczak and Templeton (2003) among five Australian secondary school students with AS without intellectual difficulties. The tendency to see family members or themselves as their friend, however, appears unique to Korean learners. The role of siblings as friends appears related to the expectation, rooted in the Confucian emphasis on family bonds (Hwang and Charnley 2010), that children without AS are expected to make sacrifices for the well-being of their autistic siblings.

The tendency to minimise the use of personal pronouns appears consistently in Korean and non-Korean autistic learners (e.g. Jordan 1989). However, it is important to note that the Korean language is a null-subject language. This means the subject of a sentence is often omitted by the speaker and inferred by the listener. For example, in Korean people would say ‘Am reading’ rather than 'I am reading’ (O'Grady, Yamashita, and Cho 2008), and explicitly including 'I’ may appear bookish and unnatural. Hence the minimal use of personal pronouns among the learners in this study must be interpreted cautiously.

Self-completion statements, used to assist learners’ communication, could have influenced the results, as they already included the personal pronoun (e.g. 'I feel ( $\quad$ ) if mum is sick'). However, this did not apply to those who chose to speak rather than write. Also, it does not explain why learners often referred to themselves 
by their proper name, a practice also found in non-Korean autistic learners (e.g. Jordan 1989).

\section{Ambivalence: love and hate}

Ambivalence featured frequently in the affective experience of the learners. Their bond with family members, especially with their mother, was expressed in a combination of both love and hatred. Doori named his mother first as the one he loved and as his friend, but he also hated her for spanking him. Jaeyong wrote he hated his mother, but he also wrote he wanted to see her and said he felt 'good' when seeing her. Sunghoon also loved and hated his family members. He loved his mother, but disliked her because she was angry with his father. He loved his younger sister, but disliked her because she was angry with Sunghoon himself.

These mixed feelings toward family members in general and mothers in particular may be influenced by social circumstances. Mothers have the main caregiver's role but lack domestic and professional support (Cho, Singer, and Brenner 2000) while also struggling with a sense of family shame attached to disability (Grinker and Cho 2013). These constraints, along with authoritarian parenting (Vinden 2001), may have contributed to the development of this love-hate relationship.

\section{Ambivalence: like and dislike}

Ambivalence also characterised responses to physical sensations. Asked what sounds they liked and disliked, Doori and Jaeyong responded with 'radio' for both questions. Jaeyong did not like to see a 'computer,' and in particular 'internet'.

Questioned further about what he disliked about the internet he said, 'Electromagnetic 
...' He then said he liked to see 'internet'. Sunghoon showed the same pattern with the flavour of instant noodles and sweet chocolate, and watching TV.

These experiences may have provided learners with both pleasant and unpleasant sensory perceptions. People with AS often report excruciating sensory perceptual experience in association with sound (e.g. Ward and Alar, 2000), and an ambivalence regarding 'radio' may be related to this sensitivity.

It is also possible that complex experiences were being expressed through simple language. For example, learners may have liked something that they were not supposed to like. Perhaps Jaeyong liked using computers but had been told that a computer is bad for his health because of electromagnetic waves. Sunghoon may have been warned against eating instant noodles and sweet chocolate and watching TV, but could not help liking them. Another possibility is that they focused on the part of the question that drew their attention (e.g. 'sound') instead of the whole question (e.g. 'What sound do you like/dislike?', resulting in the same answer to contradictory questions.

\section{Ambivalence: alone and together}

The learners' social interactions were also characterised by ambivalence. Mixed feelings were expressed regarding being alone or with others. Overall they preferred to be alone, but some switched between preferring to be alone and preferring to be with friends or family. Sunghoon and Woohyung varied between preferring to be alone and preferring to being with friends and family. Dongmin preferred to be alone despite feeling frightened when alone and good when with a friend.

This ambivalence may reflect a mixture of pain and satisfaction found in social interactions. As non-Korean individuals with AS without intellectual problems 
have reported painful social experiences, such as being subject to teasing (Ward and Alar 2000) and physical violence (Vincelette 2000), along with satisfaction with their friendships (Carrington, Papinczak, and Templeton 2003), this pattern appears universal.

\section{Conclusion}

This study has presented the affective experience of five Korean high school students identified with AS and cognitive difficulties who, with appropriate assistance, expressed a variety of affective experiences regarding their affections, feelings, perceptions and sensory experiences. While much of their experience appears straightforward, some appear more difficult to understand, such as the fluidity of the boundary between the perception of self and that of friends and the expressive idiosyncrasies of some of their expressions. Korean culture, especially its Confucian values, appears to influence the strength of their affection expressed for immediate family members, a tendency to see them as their friends, different perceptions of parents according to gender role, and a sense of confinement within the family circle. Some affective experiences are not culturally specific, since empathetic feelings expressed for family and friends, use of one's name instead of the personal pronoun, difficulties in social interactions, and desire for friendship reveal commonalities with non-Korean individuals with AS.

No learner in this study shows either a complete understanding of the affective experience of others or a complete absence of it. This indicates that the kind of questions most fruitfully asked of the affective nature of AS concern 'what', 'how' and 'how much', rather than 'whether or not'. These questions require a broadening of the research methods used to investigate the nature of AS (O'Neil 2008), so we can develop 'new ways of talking about autism that concentrate on assets rather than 
deficits' (Billington 2006, 11), and in this way develop responses to their styles of feeling and thinking that would assist in their education. The first step is to acknowledge that some learners with AS and cognitive difficulties can communicate their inner experience when they are empowered to communicate on their own terms.

\section{References}

Anzul, Margaret, Judith Evans, Rita King, and Dora Tellier-Robinson. 2001. "Moving beyond a deficit perspective with qualitative research methods." Exceptional Children no. 67:235-249.

Baron-Cohen, S. 1995. Mindblindness: An essay on autism and theory of mind. Cambridge, MA: MIT Press.

Billington, T. 2006. "Working with autistic children and young people: sense, experience, and the challenges for services, policies and practices." Disability \& Society no. 21 (1):1-13.

Boucher, Jill. 1996. "The inner life of children with autistic difficulties." In The inner life of children with special needs, edited by V. P. Varma, 81-94. London: Whurr Publishers.

Bovee, Jean-Paul. 2000. "A right to our own life, our own way." Focus on autism and other developmental disabilities no. 15 (4):250-252.

Braun, Virginia, and Victoria Clarke. 2006. "Using thematic analysis in psychology." Qualitative Research in Psychology no. 3:77-101.

Carrington, Suzanne, Tracey Papinczak, and Elizabeth Templeton. 2003. "A phenomenological study: The social world of five adolescents who have Asperger's Syndrome." Australian journal of learning disabilities no. 8 (3):1520.

Chamak, Brigitte, Beatrice Bonniau, Emmanuel Jaunay, and David Cohen. 2008. "What can we learn about autistic from autistic persons?" Phychotherapy and Psychosomatics no. 77:271-279.

Cho, Su-Je, George H. S. Singer, and Mary Brenner. 2000. "Adaptation and accommodation to young children with disabilities: A comparison of Korean and Korean American parents." Topics in Early Childhood Special Education no. 20:236-249.

Cox, Maureen V. 1993. Children's drawings of the human figure. Hove: Lawrence Erlbaum Associates.

Daley, Tamara C. 2002. "The need for cross-cultrual research on the pervasive developmental disorders." Transcultural psychiatry no. 39:531-550.

Ganesh, Tirupalavanam. 2011. "Children-produced drawings: An interpretetive and analytic tool for researchers." In The Sage handbook of visual research methods, edited by Margolis Eric and Pauwels Luc, 214-240. Los Angeles: Sage.

Gesaroni, Laura, and Malcolm Garber. 1991. "Exploring the experience of autism through firsthand accounts." Journal of Autism and Developmental Disorders no. 21 (3):303-313. 
Gillberg, C. L. 1992. "The Emanuel Miller Memorial Lecture 1991. Autism and autistic-like conditions: Subclasses among disorders of empathy." Journal of Child Psychology and Psychiatry, and Allied Disciplines no. 33 (5):813-842.

Gipps, Richard. 2004. "Autism and intersubjectivity beyond cognitivism and the theory of mind." Project MUSE no. 11:195-198.

Grandin, Temple. 2006. Thinking in pictures. My life with autism. New York: Vintage Books.

Grinker, Roy Richard, and Kyungjin Cho. 2013. "Border Children: Interpreting Autism Spectrum Disorder in South Korea." Ethos no. 41:46-74.

Hobson, Peter. 2008. "Wittgenstein and the developmental psychopathology of autism." New Ideas in Psychology no. 27:243-257.

Hoffman, Martin. 2000. Empathy and moral development: implications for caring and justice. Cambridge, New York: Cambridge University Press.

Hopperstad, Marit Holm. 2010. "Studying meaning in children's drawings." Journal of Early Childhood Literacy no. 10:430-452.

Howlin, P. , S. Baron-Cohen, and Julie Hadwin. 1999. Teaching children with autism to mind-read: A practical guide for teachers and parents. London: John Wiley \& Sons.

Huh, H. J. 2009. "Don't avoid 40,000 individuals on the autism spectrum." Pressian, 2 April

Humphrey, N., and S. Lewis. 2008. "'Make me normal' The views and experiences of pupils on the autistic spectrum in mainstream secondary schools." Autism no. 12 (1):23-46.

Hwang, Se Kwang, and Charnley Helen. 2010. "Honourable sacrifice: A visual ethnography of the family lives of Korean children with Autistic siblings." Children \& Society no. 24:437-448.

Hwang, Yoon Suk. 2009. Mind and Autism Spectrum Disorders: A Theory-of-Mind continuum model and typology developed from Theory-of-Mind as subjectively experienced and objectively understood, Faculty of Education and Social Work, They University of Sydney, Sydney.

Jordan, R. R. 1989. "An experimental comparison of the understanding and use of speaker-addressee personal pronouns in autistic children." British Journal of Disorders in Communication no. 24:169-172.

Kang-Yi, Christina D., Roy R. Grinker, and David S. Mandell. 2013. "Korean Culture and Autism Spectrum Disorders." Journal of Autism and Developmental Disorders no. 43:503-520.

Kim, Ji Sung, and Sue Faerman. 2013. "Exploring the relationship between culture and family-friendly programs in the Republic of Korea." European Management Journal no. 31:505-521.

Kim, Seung-Kook, and Ok-Ki Kim. 1985. The Social Maturity Scale. Seoul: Joongan Chuksung Choolpansa.

Kim, Young-Shin, Bennett Leventhal, Yun-Joo Koh, Eric Fombonne, Eugene Laska, Eun-Chung Lim, Keun-Ah Cheon, Soo-Jeong Kim, Young-Key Kim, HyunKyung Lee, Dong-Ho Song, and Roy Richard Grinker. 2011. " Prevalence of autism spectrum disorders in a total population sample." The American Journal of Psychiatry no. 168:904-912.

McGeer, Victoria. 2004. "Autistic Self-Awareness." Philosophy, Psychiatry, \& Psychology no. 11 (3):235-251.

McMullen, Penelope. 2000. "The gifted side of autism." Focus on autism and other developmental disabilities no. 15 (4):239-242. 
O'Grady, William, Yoshie Yamashita, and Sookeun Cho. 2008. "Object drop in Japanes and Korean." Language Acquisition no. 15 (1):58-68.

O'Neil, Sara. 2008. "The meaning of autism: beyond disorder." Disability \& Society no. 23 (7):787-799.

Prosser, Jon, and Catherine Burke. 2008. "Handbook of the Arts in Qualitative Research: Perspectives, methodologies, examples, and issues." In Handbook of the Arts in Qualitative Research: Perspectives, methodologies, examples, and issues, edited by Gary Knowles and Ardra Cole, 407-421. Thousand Oaks: Sage Publications.

Rogers, Kimberley, Isabel Dziobek, Jason Hassenstab, Oliver Wolf, and Antonio Convit. 2007. "Who cares? Revisiting empathy in Asperger Syndrome." Journal of Autism and Developmental Disorders no. 37:709-715.

Shanban, Mohamad Sadeg, and Hamed Mubarak Al-Awidi. 2013. "Understanding Emirati children's drawing in relation to self and identity through the interaction of social context." Journal of Research in Childhood Education no. 27:330-350.

Tammet, Daniel. 2006. Born on a blue day. London: Hodder \& Stoughton.

Vincelette, Barney. 2000. "My early years." Focus on autism and other developmental disabilities no. 15 (4):236-238.

Vinden, Penelope. 2001. "Parenting attitudes and children's understanding of mind." Cognitive Development no. 16:793-809.

Ward, Matt, and Nancy Alar. 2000. "Being autistic is part of who I am." Focus on autism and other developmental disabilities no. 15 (4):232-235. 